\title{
Enteric Neuropathy: NO, SNO in AGEs
}

\author{
Raj Kumar and Tor C. Savidge*
}

Division of Gastroenterology \& Hepatology, The University of Texas Medical Branch, Galveston, Texas 77555, USA

\begin{abstract}
Enteric neuropathy is emerging as a central theme in a range of digestive tract pathologies. Aberrant nitric oxide (NO) signaling by cellular components of the enteric nervous system or by inappropriate processing of dietary nitrite represents potential disease factors in delayed gastric emptying, diabetic gastroparesis, hypertrophic pyloric stenosis, and in inflammatory barrier dysfunction of the gut. Exploiting the neuronal nitric oxide synthase (nNOS) system to generate $\mathrm{NO}$ as a form of treatment is considered an option in these clinical disorders. Here we review the transcriptional regulation of nNOS activity and its pathophysiological role in the digestive tract. We also highlight potentially novel therapeutic strategies that exploit nNOS-derived $S$-nitrosothiols (SNO) and advanced glycation end products (AGEs).
\end{abstract}

Keywords: Enteric neuropathy, nNOS, $S$-nitrosothiol, advanced glycation end product, gastric emptying, diabetic gastroparesis, hypertrophic pyloric stenosis, inflammatory barrier dysfunction.

Nitric oxide (NO) is a unique molecule that serves many diverse biological functions by acting as an important intracellular second messenger and by providing intercellular communication [1-3]. NO, and its more stable $S$-nitrosothiol (SNO) intermediates [4], are also implicated in a number of important pathological processes. NO is synthesized by a family of P-450-like enzymes, known as nitric oxide synthases (NOS). In their active form, NOS homodimers catalyse the formation of $\mathrm{NO}$ and L-citrulline from L-arginine, using $\mathrm{O}_{2}$ and NADPH as co-substrates, and FMN, FAD, heme and tetrahydrobiopterin as cofactors [1-3]. This NOS activity originates from three different isoforms that are products of distinct genes: neuronal (nNOS), endothelial (eNOS), and inducible (iNOS) enzymes. nNOS is the predominant isoform for the generation of $\mathrm{NO}$ and $\mathrm{SNO}$ in several tissues including the central nervous system (CNS), skeletal muscle, kidney, testis, and the digestive tract $[5,6]$. In these organs, nNOS generated-NO regulates tissue gene expression, development, differentiation and regeneration.

Enteric nerves throughout the digestive tract express abundant nNOS activity, where NO acts as a key atypical neurotransmitter regulator of intestinal motility, vascular tone, blood supply, mucosal secretion, permeability and inflammation [7]. This signaling pathway constitutes an important mediator of the non-adrenergic, non-cholinergic inhibitory innervation of intestinal smooth muscle, where it causes relaxation of smooth muscle cells $[8,9]$. One major physiologic target of NO in the gut is NO-sensitive guanylyl cyclase, which catalyses the conversion of GTP into cGMP. This nucleotide mediates NO signaling through interaction with cGMP-dependent protein kinases, cGMP-regulated phosphodiesterases and cGMP-regulated ion channels. NO is also a neuropathologic agent, mediating excitotoxic cell death and neuroinflammatory cell damage. Impairment of nNOS and NO signals is important in the pathogenesis of digestive tract diseases as is evident in mice with genetic

*Address correspondence to this author at the Division of Gastroenterology, The University of Texas Medical Branch, Galveston, TX 77555, USA; Tel: (409) 7473086; Fax: (409) 7473084; E-mail: tcsavidg@utmb.edu deletions of nNOS and NO-sensitive guanylyl cyclase [10]. Significant interest is therefore focused on the possibility of exploiting the nNOS system as a therapeutic tool to modulate NO signals in the digestive tract. However, this emerging concept of targeting nitrergic signaling is hampered by a poor understanding of how nNOS is transcriptionally regulated in the gut.

\section{TRANSCRIPTIONAL REGULATION OF nNOS AC- TIVITY}

nNOS is classified as a complex gene in terms of its first exon usage and alternative splicing [11-13]. It has been shown that nNOS exons that are abundantly expressed in the human digestive tract [14-16] are driven by separate promoters, at least in HeLa cells. Use of multiple alternative promoters permits cell-, tissue-, and site-specific transcriptional regulation of nNOS under different physiological and pathophysiological conditions. Although nNOS is constitutively expressed in the gut, several studies have indicated that its expression is also regulated by transcriptional control processes. However, not much is known about this specific transcriptional regulation. The genomic organization of human nNOS is known and contains several putative transcription factor binding sites such as AP-1, Sp-1, NFKB, and half sites of glucocorticoid response elements [16-18]. nNOS expression is often also associated with co-induction of transcriptional factors such as c-Jun, which binds to the AP-1 site. In addition, nNOS activity is regulated by estrogens via the estrogen receptor (ER), and AP-1 transcription factors may be involved in the up regulation of nNOS and ER by estrogen [19]. These data indicate the presence of multiple promoters that facilitate differential transcriptional regulation of nNOS.

The rabbit nNOS promoter has a high GC content, and canonical TATA and CCAAT boxes are absent in proximal regions upstream of the transcription start sites. Although the absence of a TATA box does not necessarily affect transcription rates, it can result in promiscuous initiation of transcription by RNA polymerase II (Pol II), resulting in multiple initiation sites. In several eukaryotic genes, it has been observed that promoters lacking a TATA box are recognized by Sp-1 $[18,20]$. Because the minimal promoter of nNOS exon 
$1 \mathrm{c}$ is $\mathrm{GC}$-rich, TATA-less, and $\mathrm{Sp}-1$ regulated, it resembles those for constitutively expressed genes, including eNOS [21-23] where promoter regulation is not well understood. In addition, it has been shown that GC-rich promoter regions lacking a canonical TATA box bind $\mathrm{Sp}-1$ molecules that interact with multiple components of the transcriptional machinery $[24,25]$. Therefore $\mathrm{Sp}-1$ plays a critical role in the assembly of the transcription initiation complex.

\section{TRANSCRIPTIONAL REGULATION OF nNOS AC- TIVITY IN THE DIGESTIVE TRACT}

Several 5' mRNA splice variants of nNOS are expressed in the digestive tract. These splice variants differ in the first untranslated exon due to alternative promoter usage and show specific expression at various sites in the digestive tract. Three variants encode for $\mathrm{nNOS}_{\alpha}$, and two others for $\mathrm{nNOS}_{\beta}$ and $\mathrm{nNOS}_{\gamma}$. The $\mathrm{nNOS}_{\alpha}$ protein contains a specific $\mathrm{N}$-terminal PDZ domain, which is important for proteinprotein interactions involving nNOS and other regulatory proteins [26-28]. For example, the PDZ domain interacts with postsynaptic density protein PSD-95 that also binds to glutamate NMDA receptors, thus allowing an efficient stimulation of nNOS activity by calcium ions entering through NMDA channels. Within the N-terminal region, $\mathrm{nNOS}_{\alpha}$ also possesses a binding domain for nNOS protein inhibitor (PIN) and nitric oxide synthase interacting protein (NOSIP). By contrast, both $\mathrm{nNOS}_{\beta}$ and $\mathrm{nNOS}_{\gamma}$ are $\mathrm{N}$ terminally truncated proteins and thus lack these proteinprotein interaction domains (Fig. 1). The catalytic activity of $\mathrm{nNOS}_{\beta}$ is approximately $80 \%$ of $\mathrm{nNOS}_{\alpha}$, whereas $\mathrm{nNOS}_{\gamma}$ is functionally inert [29]. Thus, $\mathrm{nNOS}_{\gamma}$ may function as a dominant-negative nNOS variant in the digestive tract. Other studies have also suggested that both nNOS $_{\beta}$ and nNOS $_{\gamma}$ protein variants are generated by translation of $\mathrm{nNOS}_{\beta}$ mRNA, indicating that post-transcriptional and posttranslational mechanisms regulate the expression of active $\mathrm{nNOS}_{\beta}$ or inhibitory $\mathrm{nNOS}_{\gamma}$ from the same mRNA species.

A more recent report has demonstrated that nNOS splice variants have a differential site-specific mRNA expression in the human gastrointestinal tract [30]. All nNOS splice forms were expressed in the human colon. However, the nNOS $\gamma$ isoform was not detected in the stomach and small intestine $[30,31]$. Findings in $\mathrm{nNOS}_{\alpha}$ mutant mice support the view that nNOS plays a functional role in the digestive tract [32, 33]. These animals display a disease phenotype that closely resembles hypertrophic pyloric stenosis, with delayed gastric emptying of solids and fluids. However, due to the continued expression of alternative $\mathrm{nNOS}_{\beta}$ and $\mathrm{nNOS}_{\gamma}$ splice variants the disease pathology in other gastrointestinal regions is less severe when compared with targeted deletion of NOsensitive guanylyl cyclase in mice [10]. These studies indicate potentially different functional roles for nNOS splice variants in the murine digestive tract.

To support this view, $\mathrm{nNOS}_{\alpha}$, but not $\mathrm{nNOS}_{\beta}$ appears to regulate pyloric sphincter relaxation and gastric stasis with delayed gastric emptying $[32,33]$. $\mathrm{nNOS}_{\alpha}$ is the only isoform possessing a PDZ/GLGF motif [31]. This motif is crucial for functional nNOS dimerization and for other important protein-protein interactions, for example involving PSD-95 and PSD-93 which co-ordinate $\mathrm{nNOS}_{\alpha}$ to NMDA receptor
(A)
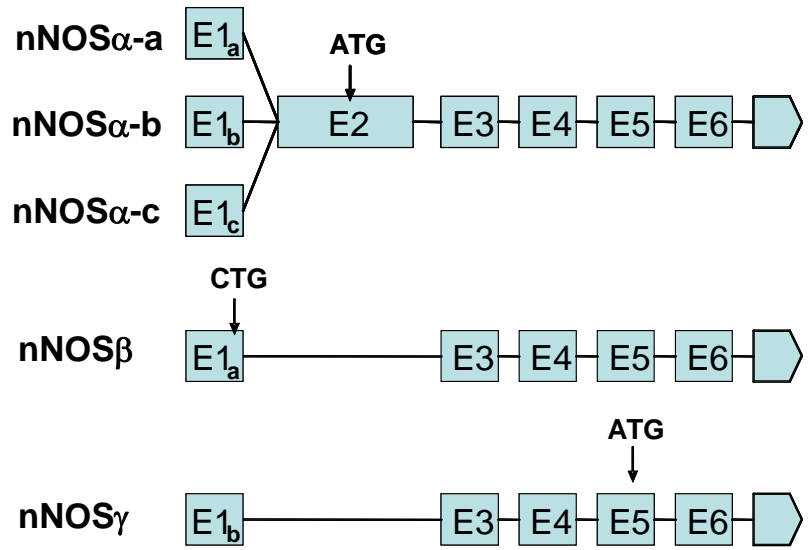

(B)

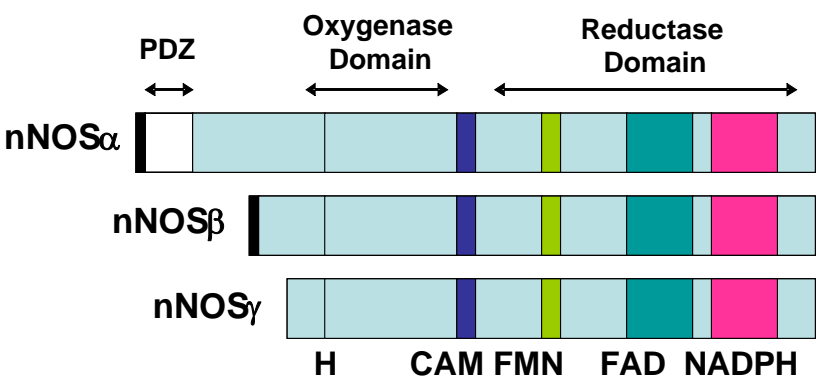

Fig. (1). Diagrams showing different isoforms of neuronal nNOS. Schematic illustration of exon structure generated by alternative splicing of the neuronal nitric oxide synthase (nNOS) gene, based upon [14]. E denotes exon. (A) Three alternative transcripts (exon $1 \mathrm{a} /$ exon 2 , exon $1 \mathrm{~b} /$ exon 2 , and exon $1 \mathrm{c} /$ exon 2 ) driven by separate promoters and spliced to the common exon 2 are shown. Different first exons are located in the $5^{\prime}$ untranslated region of nNOS mRNA and therefore encode for nNOS $\alpha$ a-c. Bottom: Exon structure of the $\mathrm{nNOS} \beta$ and nNOS $\gamma$ transcripts (exon $1 \mathrm{a} /$ exon 3 and exon 1b/exon3) lacking exon 2. Translational initiation codons (ATG, CTG) are indicated by a vertical arrow. Untranslated first exons $1 \mathrm{a}, 1 \mathrm{~b}$, and $1 \mathrm{c}$ are spliced to a common second exon containing the AUG starter methionine for initiation of translation. Exon deletion by splicing of exon 1a to exon 3 results in the formation of nNOS $\beta$, with a loss of the genuine translational initiation site located at exon 2, containing a non-canonical initiation region within exon $1 \mathrm{a}(\mathrm{CTG})$, resulting in an $\mathrm{NH}_{2}$-terminally truncated $\mathrm{nNOS} \beta$ protein. (B) Schematic presentation of nNOS protein isoforms. $\mathrm{nNOS} \alpha$ contains a $\mathrm{NH}_{2}$-terminal PDZ/GLGF-domain, a motif of $\sim 100$ amino acids, that can mediate an association to other PDZ-containing proteins, whereas both $\mathrm{nNOS} \beta$ and $\mathrm{nNOS} \gamma$ lack this domain. $\mathrm{H}$, consensus binding sites for heme; CAM, for calmodulin; FMN, for flavin mononucleotide; and $\mathrm{FAD}$, for flavin adenine dinucleotide.

subunits. Differences in the $\mathrm{NH}_{2}$-terminal protein structure are therefore likely to confer functional distinctions between $\mathrm{nNOS}_{\alpha}, \mathrm{nNOS}_{\beta}$, and $\mathrm{nNOS}_{\gamma}$ variants [33,34]. A recent report has highlighted the functional importance of this PDZ domain interaction in regulating $\mathrm{nNOS}$ activity in the digestive tract [35]. In this report reduced $\mathrm{nNOS}_{\alpha}$ dimerization, but not total nNOS expression, significantly altered solid gastric emptying and gastric antrum nitrergic relaxation in female rats, resulting in gastroparesis. Since the dimerization domain in nNOS is located in the $\mathrm{N}$-terminal region that is lacking in $\mathrm{nNOS}_{\beta}$ and $\mathrm{nNOS}_{\gamma}$ isoforms, it is logical to hy- 
pothesize that these different nNOS splice variants have differential physiological roles. Therefore, it is of great clinical interest to determine further the spatio-temporal expression of nNOS variants in the digestive tract.

Diversity of nNOS mRNAs in different tissues and developmental stages is reported to be a major characteristic of nNOS gene expression [30]. Several studies indicate such tissue specific nNOS promoter-usage in the digestive tract. All three variants are expressed in gastric fundus and antrum, duodenum, proximal colon and rectum [29, 30, 36]. There is also evidence for promiscuous nNOS expression in nonneuronal cell types in the digestive tract. In the CNS, although all parenchymal cells have the capacity to synthesize NO, only neurons and astroglial cells express all the molecular components required for NO-cGMP-dependent protein kinase signaling. Recent evidence implicates this pathway in the regulation of important aspects of astroglial physiologycalcium homeostasis, gene expression and survival-that are relevant for neuronal function [37]. Although initially controversial, there is now solid evidence that nNOS activity is also present in astrocytes. The first indication of the expression of calcium-dependent NOS activity in astrocytes was obtained using primary cultures from rat brain cortex. Cultured enteric glial cells from rat myenteric plexus also appear to express nNOS immunoreactivity in a similar fashion to astrocytes and may therefore represent an alternative source for nNOS-generated $\mathrm{NO}$ in the digestive tract (Fig. 2). We have previously demonstrated that this NOS activity contributes to the synthesis of SNO by enteric glial cells, and that this family of NO-derived signaling molecules plays an important role in regulating intestinal permeability and inflammation [38]. Enteric glial cells may also represent an important rate-limiting step in nNOS catalytic activity. Enteric glia are the only cells within the enteric nervous system to express L-arginine and this is transferred directly to enteric neurons [7]. Consequently, this represents a potentially important regulatory substrate requirement for nNOS activity, and we have previously demonstrated that genetic ablation of enteric glia in transgenic mouse models results in aberrant nNOS expression and gut pathology [38-40]. These findings argue for a complex regulation of nNOS gene expression by cell- and region-specific transcriptional and post-translational control.

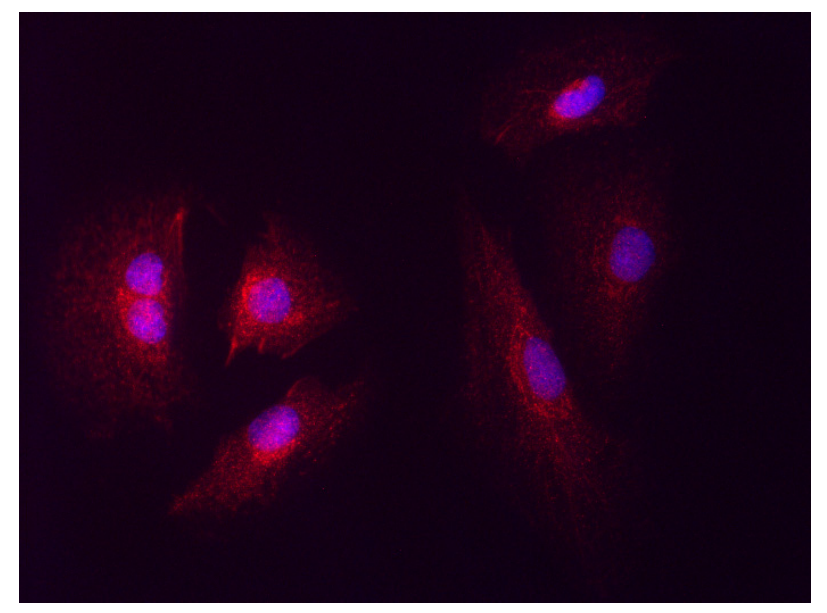

Fig. (2). nNOS expression in cultured rat enteric glial cells. Immunoreactivity for nNOS protein is shown in red and nuclei are counterstained blue (magnification x400).

\section{nNOS ACTIVITY AND GUT PATHOLOGY}

Intense effort is currently underway to define the pathophysiological role for aberrant nNOS gene regulation in the digestive tract. Although it is still not precisely clear how nNOS dysfunction contributes to gut pathology, several reports indicate that a reduction in nNOS activity may be responsible for motility disorders and other digestive tract diseases [35, 41, 42] (Table 1). Impaired nNOS synthesis in the myenteric plexus has been described as a potential disease factor in the pathogenesis of several clinical conditions including achalasia $[43,44]$ and diabetic gastroparesis $[35,36$, 45]. Infantile hypertrophic pyloric stenosis is also associated with decreased nNOS expression in the hypertrophied circular muscle sphincter [30]. A deficiency in nNOS innervation may also contribute to the pathogenesis of aperistalsis of the esophagus in patients with congenital esophageal stenosis. Aberrant NO signaling is present in patients with functional dyspepsia [46], although it is unclear whether this is due to a reduction in $\mathrm{NO}$ release or nNOS expression in the gastric myenteric plexus. Besides these effects on $\mathrm{NO} / \mathrm{nNOS}$, gastric relaxation in diabetes is affected mainly by impaired nNOS expression in the gastric myenteric plexus [47-49]. In addition, during pregnancy delayed gastric emptying may in part be due to abnormal NO activity [50]. A pathogenic role has also been suggested in aging, with nNOS expression and activity decreasing in the large intestine [51]. Thus, aberrant nNOS activity is implicated in several important gut diseases, notably in gastrointestinal dysmotility and diabetic gastropathy $[52,53]$. Huber et al. have suggested that under certain pathological conditions, this may be due to differences in transcriptional control, enzymatic activity, and subcellular localization of nNOS splice variants [54]. Alternative splicing of nNOS should therefore be considered in functional disorders of the digestive tract.

Table 1. nNOS Expression in Gastrointestinal Disease

\begin{tabular}{|c|c|c|c|c|}
\hline nNOS & Species & Disease & Tissue & Ref. \\
\hline \hline down & rat & Diabetes & duodenum & {$[9]$} \\
\hline down & human & Achalasia & esophageal & {$[4]$} \\
\hline down & human & Chagas disease & large intestine & {$[34]$} \\
\hline up & human & Pseudo-obstruction & small intestine & {$[31]$} \\
\hline down & human & Pyloric stenosis & pylorus & {$[6]$} \\
\hline down & human & Functional Dyspepsia & stomach & {$[76]$} \\
\hline down & human & Hirschsprung's disease & colon & {$[32]$} \\
\hline down & dog & Iron deficiency & gallbladder & {$[75]$} \\
\hline down & rat & Colitis & colon & {$[33]$} \\
\hline down & rat & Vagotomy & stomach & {$[77]$} \\
\hline
\end{tabular}

\section{S-NITROSOTHIOL SIGNALS IN GUT DISEASE}

Another important and largely unexplored nNOS signaling pathway in the digestive tract is conferred via the generation of $S$-nitrosothiols (SNOs). Under normal steady-state conditions, these NO-derived SNO metabolite intermediates provide cell signals that function largely independently of NO-sensitive guanylyl cyclase $[4,55,56]$. However, at higher 
tissue concentrations SNO may also activate this signaling pathway. $S$-nitrosylation reactions typically regulate specific physiologic and pathophysiologic signaling cascades by directly modifying functionally important cysteine residues on proteins. $S$-nitrosylation of protein thiols may occur as a result of $S$-nitrosylation by small molecular weight $S$ nitrosothiols such as S-nitrosoglutahione (GSNO) or by exposure of specific redox-active cysteine residues to NO. Generally, specific protein thiols forming part of a consensus motif are targeted by $S$-nitrosylation $[4,55,56]$. For example, the ryanodine response calcium channel of skeletal muscle has many reduced cysteines, yet only one (Cys3635) is selectively $S$-nitrosylated to achieve calmodulin-dependent NOmediated modulation of channel activity. Excessive $S$ nitrosylation of other thiol residues alters the bioactivity of this channel. Further studies are needed to evaluate the pathophysiological importance of nNOS-derived SNO signals in the digestive tract. However, as aberrant SNO signals have already been implicated in CNS, respiratory and cardiovascular disease [57,58], a precedent exists to examine the role of SNO signals in gut pathology. Of particular relevance to this review, SNO signals have been implicated in the survival of neurons in the CNS [59]. In addition, a substantial quantity of SNO is generated in the stomach from dietary nitrite that acts as a 'prodrug' in this tissue [60, 61]. Dietary sources of NO production, especially from foods rich in heme-containing red meat, can constitute up to $20 \%$ of total body NO production, and a significant quantity is converted into stable SNO-intermediate signaling molecules in the digestive tract. Since exogenous SNO is known to augment Sp-1 regulated gene expression [20,56], therapeutically delivered SNO and/or by modulating dietary SNO production may represent possible options to alter intestinal nNOS activity.

\section{GASTROINTESTINAL DYSMOTILITY AND DIA- BETIC GASTROPATHY}

Gastrointestinal smooth muscle cell activity is controlled by contractile cholinergic and relaxant non-adrenergic noncholinergic (NANC) neurons in the myenteric plexus. Several reports indicate an involvement of decreased or increased NANC relaxation in the pathophysiology of functional gastrointestinal motility disorders. Although nNOSgenerated NO is the primary inhibitory NANC neurotransmitter, it is likely that several transmitter molecules function in conjunction with this to provide NANC inhibitory signals in regulating gut motility [62,63]. An elegant experimental example of the functional importance of NO signaling in gut motility was demonstrated following genetic ablation of NOsensitive guanylyl cyclase in mice [10]. These transgenic animals develop fatal gastrointestinal obstruction, and a subgroup died following weaning due to a grossly enlarged and dilated caecum. Weaning of these animals onto a fiber-free diet circumvented mortality.

Other studies indicate a role for nNOS-derived $\mathrm{NO}$ in inhibiting esophageal smooth muscle function [64], and a loss of NO activity has been demonstrated in esophageal dysmotility $[65,66]$. A role for NO has also been demonstrated in gastric emptying, slow-transit constipation, and small bowel motility [67-69]. An early loss of inhibitory enteric neurons in the pylorus and antrum correlates with delayed gastric emptying in patients receiving treatment. It has also been shown that myenteric nNOS expression in the intestine, unlike in the stomach, is not dependent on vagal innervation. $\mathrm{NO} / \mathrm{nNOS}$ have powerful effects on gastrointestinal motility by controlling pyloric flow and mediate intestinal feedback inhibition of gastric emptying. Inhibition of nNOS is also reported to enhance antral contractions and disrupt fed motor patterns in animals. Failure of NO inhibition to alter the postprandial pattern of the human duodenum has been reported previously, and may relate to dosing, density of nNOS positive neurons in specific duodenal sites, or site-specific splice variants of NOS.

Delayed gastric emptying, and early satiety is also a common clinical condition in diabetic patients, especially in women. Although the precise disease mechanisms are unclear, there is evidence indicating that impaired pyloric inhibition contributes to gastropathy in diabetic mellitus. A critical role for NO in gastropyloris has been established, and loss of pyloric nNOS is associated with gastric outflow obstruction. Using transgenic diabetic mouse models, delayed gastric emptying correlates with loss of nNOS expression $[70,71]$. Treatment of these diabetic animals with insulin reverses the abnormal physiology and restores pyloric nNOS expression. In addition, use of sildenafil to augment NOsignaling in these animals reversed the delayed gastric emptying. This indicates that diabetic gastropathy in animal models reflects a reversible down regulation of nNOS activity.

Even though diabetic intestinal dysfunction is relatively common, this has received relatively little attention compared with gastroparesis. The term diabetic enteropathy is often used to explain disturbances in bowel function such as chronic diarrhea, and occurs in $15 \%$ or more of diabetic patients $[70,71]$. nNOS deficiency would be expected to slow gastrointestinal transit, but paradoxically, this may also result in diarrhea because of secondary bacterial overgrowth which is a known problem in diabetic patients. Diabetic autonomic neuropathy can lead to diabetic gastropathy due to an impairment of nitrergic neurons [70-72]. Decreased nNOS expression is evident in the pylorus of diabetic animals and in patients [70,71]. A recent study has also shown that nitrergic neurons innervating the gastric pylorus of diabetic rats go through a two-phase degenerative process [72]: firstly, the nNOS content is decreased in the axons, but not in the cell bodies. This phase is reversible by insulin treatment and is not associated with neurodegenerative changes. In the second phase neurons undergo a degenerative process and lose their nNOS content completely. This neurodegenerative process is selective for nitrergic neurons, is irreversible by insulin treatment and is caused by apoptotic cell death in the ganglia. As NO-generated SNO plays an important signaling role in preventing neuronal death in the CNS, it is important to examine what role, if any, SNO plays in diabetic gastropathy. This is particularly relevant since gastric tissues generate and store SNO from dietary nitrite [61, 62], and this family of signaling molecule modulates neuronal function and survival, mucosal fluid secretion and barrier function [38]. Enhanced intestinal permeability is also evident in diabetic patients and may constitute another related disease factor. 
Current treatments for diabetic gastropathy are based on using drugs that increase stomach contractions. Because of the findings that abnormalities in diabetic gastropathy are primarily associated with NO-mediated nonadrenergic, noncholinergic (NANC) relaxation in the pylorus rather than the contractile component of gastropyloric function, drugs that enhance the effects of nNOS-derived NO would be more effective by causing pyloric relaxation. An interesting therapeutic approach that is currently being testing is modulation of nNOS activity using advanced glycation end products (AGEs) [73]. This is a heterogeneous group of molecules formed by non-enzymatic attachment of reducing sugars to protein amino groups. Although some AGE formation occurs under normal physiological conditions, this process is significantly accelerated in uncontrolled diabetes due to the abundant availability of glucose. Although glycation can by itself lead to structural and functional changes in the target protein, a more important consequence may be the ability of the conjugate to activate the receptor for advanced glycation end products (RAGE). Serum and tissue AGE levels (as well as other potential ligands for RAGE) are elevated in diabetes and have been linked to many other complications of diabetes mellitus, including those affecting the blood vessels, kidneys, nerves and retina.

We have recently shown in experimental diabetes that significantly increased levels of AGEs are detected in serum and in the gastric pylorus [73]. Furthermore, in diabetic rats significant protection of myenteric nNOS expression was conferred by strategies aimed at counteracting AGE. Measurement of intestinal function in these studies provided the first reported evidence that AGE signaling is implicated in the pathogenesis of enteric neuropathy. Activation of RAGE, a multi-ligand member of the immunoglobulin superfamily, triggers a broad spectrum of intracellular signaling pathways that include the NFKB, JAk/stat, p21 ras, and MAP kinase families. Until recently, little or no information was available regarding the expression of this signaling system in the digestive tract, although one previous autopsy study of patients with amyloid polyneuropathy has demonstrated the presence of both RAGE and AGE within myenteric ganglia [74]. These results indicate that countering the AGE-RAGE signaling pathway may be a major target for diabetes-related gut complications, especially in relation to aberrant nNOS expression.

\section{SUMMARY AND PERSPECTIVES}

The pathogenic role for nNOS-derived NO in the digestive tract remains an area of active investigation. Aberrant nNOS expression is evident in a wide range of gut diseases and dysregulation is likely mediated via altered promoter usage, activation or suppression by disease-specific transcription factors, and possibly by dietary nitrite generated NO and SNO (Fig. 3). Characterization of such disease factors will provide a better understanding of molecular mechanism(s) that may be therapeutically targeted in an attempt to exploit the nNOS-derived NO system for disease prevention. Novel perspectives that may be applied in the pursuit of these endeavors include focusing efforts on SNO and AGEs signaling pathways as these are largely unexplored in the digestive tract.

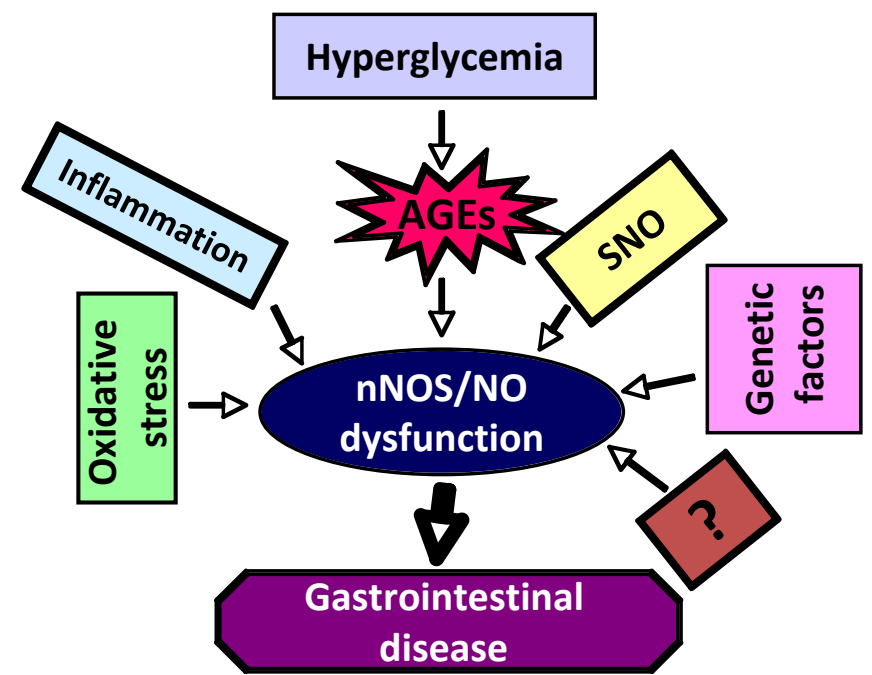

Fig. (3). Schematic summary of putative signaling pathways implicated in the dysregulation of nNOS activity during gastrointestinal disease. Question mark represents unknown signaling pathways that influence nNOS activity.

\section{ACKNOWLEDGEMENT}

This work was supported by The Eli and Edythe L. Broad Foundation.

\section{REFERENCES}

[1] Ignarro LJ. Physiology and pathophysiology of nitric oxide. Kidney Int Suppl 1996; 55: S2-5.

[2] Andrew PJ, Mayer B. Enzymatic function of nitric oxide synthases. Cardiovasc Res 1999; 43: 521-31.

[3] Li H, Poulos TL. Structure-function studies on nitric oxide synthases. J Inorg Biochem 2005; 99: 293-305.

[4] Jaffrey SR, Erdjument-Bromage H, Ferris CD, Tempst P, Snyder SH. Protein $S$-nitrosylation: a physiological signal for neural nitric oxide. Nat Cell Biol 2001; 3: 193-97.

[5] Wang Y, Newton DC, Marsden PA. Neuronal NOS: gene structure, mRNA diversity, and functional relevance. Crit Rev Neurobiol 1999; 13: 21-43.

[6] Stamler JS, Meissner G. Physiology of nitric oxide in skeletal muscle. Physiol Rev 2001; 81: 209-37.

[7] Schemann M, Neunlist M. The human enteric nervous system. Neurogastroenterol Motil 2004; 16: 55-59.

[8] Van Geldre LA, Lefebvre RA. Interaction of NO and VIP in gastrointestinal smooth muscle relaxation. Curr Pharm Des 2004; 10: 2483-97.

[9] Takahashi T. Pathophysiological significance of neuronal nitric oxide synthase in the gastrointestinal tract. J Gastroenterol 2003; 38: 421-30.

[10] Friebe A, Mergia E, Dangel O, Lange A, Koesling D. Fatal gastrointestinal obstruction and hypertension in mice lacking nitric oxidesensitive guanylyl cyclase. Proc Natl Acad Sci USA 2007; 104: 7699-04.

[11] Boissel JP, Zelenka M, Gödtel-Armbrust U, Feuerstein TJ, Förstermann U. Transcription of different exons 1 of the human neuronal nitric oxide synthase gene is dynamically regulated in a celland stimulus-specific manner. Biol Chem 2003; 384: 351-62.

[12] Secondo A, Sirabella R, Formisano L, et al. Involvement of PI3'-K, mitogen-activated protein kinase and protein kinase $B$ in the upregulation of the expression of nNOSalpha and nNOSbeta splicing variants induced by PRL-receptor activation in GH3 cells. J Neurochem 2003; 84: 1367-77.

[13] Newton DC, Bevan SC, Choi S, et al. Translational regulation of human neuronal nitric-oxide synthase by an alternatively spliced 5'untranslated region leader exon. J Biol Chem 2003; 278: 636-44.

[14] Saur D, Paehge H, Schusdziarra V, Allescher HD. Distinct expression of splice variants of neuronal nitric oxide synthase in the human gastrointestinal tract. Gastroenterology 2000; 118: 849-958. 
[15] Huber A, Saur D, Kurjak M, Schusdziarra V, Allescher HD. Characterization and splice variants of neuronal nitric oxide synthase in rat small intestine. Am J Physiol 1998; 275: G1 146-56.

[16] Vannucchi MG, Corsani L, Bani D, Faussone-Pellegrini MS. Myenteric neurons and interstitial cells of Cajal of mouse colon express several nitric oxide synthase isoforms. Neurosci Lett 2002; 326: 191-95.

[17] Molero L, García-Durán M, Diaz-Recasens J, Rico L, Casado S, López-Farré A. Expression of estrogen receptor subtypes and neuronal nitric oxide synthase in neutrophils from women and men: regulation by estrogen. Cardiovasc Res 2002; 56: 43-51.

[18] Jeong Y, Won J, Kim C, Yim J. 5'-Flanking sequence and promoter activity of the rabbit neuronal nitric oxide synthase (nNOS) gene. Mol Cells 2000; 10: 566-74.

[19] Garban HJ, Marquez-Garban DC, Pietras RJ, Ignarro LJ. Rapid nitric oxide-mediated $S$-nitrosylation of estrogen receptor: Regulation of estrogen-dependent gene transcription. Proc Natl Acad Sci USA 2005; 102: 2632-36.

[20] Zaman K, Palmer LA, Doctor A, Hunt JF, Gaston B. Concentration-dependent effects of endogenous $S$-nitrosoglutathione on gene regulation by specificity proteins Sp3 and Sp1. Biochem J 2004; 380: 67-74.

[21] Böhm SK, Gum JR Jr, Erickson RH, Hicks JW, Kim YS. Human dipeptidyl peptidase IV gene promoter: tissue-specific regulation from a TATA-less GC-rich sequence characteristic of a housekeeping gene promoter. Biochem J 1995; 311: 835-43.

[22] Xing F, Jiang Y, Liu J, et al. Role of AP1 element in the activation of human eNOS promoter by lysophosphatidylcholine. J Cell Biochem 2006; 98: 872-84.

[23] Wu KK. Regulation of endothelial nitric oxide synthase activity and gene expression. Ann N Y Acad Sci 2002; 962: 122-30.

[24] Cook T, Gebelein B, Urrutia R. Sp1 and its likes: biochemical and functional predictions for a growing family of zinc finger transcription factors. Ann N Y Acad Sci 1999; 880: 94-102.

[25] Wegner M. Transcriptional control in myelinating glia: flavors and spices. Glia 2000; 31: 1-14.

[26] Chanrion B, Mannoury la Cour C, Bertaso F, et al. Physical interaction between the serotonin transporter and neuronal nitric oxide synthase underlies reciprocal modulation of their activity. Proc Natl Acad Sci USA 2007; 104: 8119-24.

[27] Riefler GM, Firestein BL. Binding of neuronal nitric-oxide synthase (nNOS) to carboxyl-terminal-binding protein (CtBP) changes the localization of $\mathrm{CtBP}$ from the nucleus to the cytosol: a novel function for targeting by the PDZ domain of nNOS. J Biol Chem 2001; 276: 48262-68

[28] Hashida-Okumura A, Okumura N, Iwamatsu A, Buijs RM, Romijn HJ, Nagai K. Interaction of neuronal nitric-oxide synthase with alpha1-syntrophin in rat brain. J Biol Chem 1999; 274: 11736-741.

[29] Brenman, JE, Chao DS, Gee SH, et al. Interaction of nitric oxide synthase with the postsynaptic density protein PSD-95 and a1syntrophin mediated by PDZ domains. Cell 1996; 84: 757-67.

[30] Saur D, Neuhuber WL, Gengenbach B, Huber A, Schusdziarra V, Allescher HD. Site-specific gene expression of nNOS variants in distinct functional regions of rat gastrointestinal tract. Am J Physiol Gastrointest Liver Physiol 2002; 282: G349-58.

[31] Stricker NL, Christopherson KS, Yi BA, et al. PDZ domain of neuronal nitric oxide synthase recognizes novel C-terminal peptide sequences. Nat Biotechnol 1997; 15: 336-42.

[32] Mashimo H, Kjellin A, Goyal RK. Gastric stasis in neuronal nitric oxide synthase-deficient knockout mice. Gastroenterology 2000; 119: 766-73.

[33] Huang PL, Dawson TM, Bredt DS, Snyder SH, Fishman MC. Targeted disruption of the neuronal nitric oxide synthase gene. Cell 1993; 75: 1273-86.

[34] Saur D, Paehge H, Schusdziarra V, Allescher HD. Distinct expression of splice variants of neuronal nitric oxide synthase in the human gastrointestinal tract. Gastroenterology 2000; 118: 849-58.

[35] Gangula PR, Maner WL, Micci MA, Garfield RE, Pasricha PJ. Diabetes induces sex-dependent changes in neuronal nitric oxide synthase dimerization and function in the rat gastric antrum. Am J Physiol Gastrointest Liver Physiol 2007; 292: G725-33.

[36] Adeghate E, al-Ramadi B, Saleh AM, et al. Increase in neuronal nitric oxide synthase content of the gastroduodenal tract of diabetic rats. Cell Mol Life Sci 2003; 60: 1172-79.

[37] Catania MV, Arconica E, Yankaya B, Troost D. Increased expression of neuronal nitric oxide synthase spliced variants in reactive astrocytes of amylotrophic lateral sclerosis human spinal cord. J Neurosci 2001; 148: 1-5.

[38] Savidge TC, Newman P, Pothoulakis C, et al. Enteric glia regulate intestinal barrier function and inflammation via release of $S$ nitrosoglutathione. Gastroenterology 2007; 132: 1344-58.

[39] Bush TG, Savidge TC, Freeman TC, et al. Fulminant jejuno-ileitis following ablation of enteric glia in adult transgenic mice. Cell 1998; 93: 189-201.

[40] Cornet A, Savidge TC, Cabarrocas J, et al. Enterocolitis induced by autoimmune targeting of enteric glial cells: A possible mechanism in Crohn's disease. Proc Nat Acad Sci USA 2001; 98: 13306-311.

[41] Demedts I, Geboes K, Kindt S, et al. Neural mechanisms of early postinflammatory dysmotility in rat small intestine. Neurogastroenterol Motil 2006; 18: 1102-11.

[42] Dijkstra G, van Goor H, Jansen PL, Moshage H. Targeting nitric oxide in the gastrointestinal tract. Curr Opin Investig Drugs 2004; 5: 529-36.

[43] Kono T, Chisato N, Ebisawa Y, et al. Impaired nitric oxide production of the myenteric plexus in colitis detected by a new bioimaging system. J Surg Res 2004; 117: 329-38.

[44] Mizuta $Y$, Isomoto $H$, Takahashi $T$. Impaired nitrergic innervation in rat colitis induced by dextran sulfate sodium. Gastroenterology 2000; 118: 714-23.

[45] Iwasaki H, Kajimura M, Osawa S, et al. A deficiency of gastric interstitial cells of Cajal accompanied by decreased expression of neuronal nitric oxide synthase and substance $P$ in patients with type 2 diabetes mellitus. J Gastroenterol 2006; 41: 1076-87.

[46] Walecka-Kapica E, Klupińska G, Harasiuk A, Felicka E, Foryś S, Chojnacki C. The influence of melatonin on concentration of nitric oxide metabolites in gastric juice in subjects with functional dyspepsia. Pol Merkur Lekarski 2007; 22: 332-35.

[47] Shotton HR, Adams A, Lincoln J. Effect of aminoguanidine treatment on diabetes-induced changes in the myenteric plexus of rat ileum. Auton Neurosci 2007; 132: 16-26.

[48] Shotton HR, Adams A, Lincoln J. Diabetes only affects nitric oxide synthase-containing myenteric neurons that do not contain heme oxygenase 2. Brain Res 2006; 1068: 248-56.

[49] Surendran S, Kondapaka SB. Altered expression of neuronal nitric oxide synthase in the duodenum longitudinal muscle-myenteric plexus of obesity induced diabetes mouse: implications on enteric neurodegeneration. Biochem Biophys Res Commun 2005; 338: 919-22.

[50] Shah S, Nathan L, Singh R, Fu YS, Chaudhuri G. E2 and not P4 increases NO release from NANC nerves of the gastrointestinal tract: implications in pregnancy. Am J Physiol Regul Integr Comp Physiol 2001; 280: R1546-54.

[51] Gabella B. Fall in the number of myenteric neurons in aging guinea pigs. Gastroenterology 1989; 96: 1487-93.

[52] Demedts I, Geboes K, Kindt S, et al. Neural mechanisms of early postinflammatory dysmotility in rat small intestine. Neurogastroenterol Motil 2006; 18: 1102-11.

[53] Patil CS, Singh VP, Kulkarni SK. Modulatory effect of sildenafil in diabetes and electroconvulsive shock-induced cognitive dysfunction in rats. Pharmacol Rep 2006; 58: 373-80.

[54] Huber A, Saur D, Kurjak M, Schusdziarra V, Allescher HD. Characterization and splice variants of neuronal nitric oxide synthase in rat small intestine. Am J Physiol Gastrointest Liver Physiol 1998, 275: G1146-G1156.

[55] Stamler JS, Toone EJ, Lipton SA, Sucher NJ. (S)NO signals: Translocation, regulation, and a Consensus Motif. Neuron 1997; 18: 691-96.

[56] Gaston BM, Carver J, Doctor A, Palmer LA. $S$-nitrosylation signaling in cell biology. Mol Interv 2003; 3: 253-63.

[57] Que LG, Liu L, Yan Y, et al. Protection from experimental asthma by an endogenous bronchodilator. Science 2005; 308: 1618-21.

[58] Schonhoff CM, Matsuoka M, Tummala H, et al. S-nitrosothiol depletion in amyotrophic lateral sclerosis. Proc Natl Acad Sci 2006; 103: 2404-09.

[59] He J, Wang T, Wang P, Han P, Yin Q, Chen C. A novel mechanism underlying the susceptibility of neuronal cells to nitric oxide: the occurrence and regulation of protein $S$-nitrosylation is the checkpoint. J Neurochem 2007; 102: 1863-74.

[60] Suscheck CV, Schewe T, Sies H, Kröncke KD. Nitrite, a naturally occurring precursor of nitric oxide that acts like a 'prodrug'. Biol Chem 2006; 387: 499-506. 
[61] Kuhnle GGC, Story GW, Reda T, et al. Diet-induced endogenous formation of nitroso compounds in the GI tract. Free Rad Biol Med 2007; 43: 1040-47.

[62] Tomita R, Munakata K, Tanjoh K. Role of non-adrenergic noncholinergic inhibitory nerves in the colon of patients with ulcerative colitis. J Gastroenterol 1998; 33: 48-52.

[63] Pederzoli A, Conte A, Tagliazucchi D, Gambarelli A, Mola L. Occurrence of two NOS isoforms in the developing gut of sea bass Dicentrarchus labrax (L.). Histol Histopathol 2007; 22: 1057-64.

[64] Kim CD, Goyal RK, Mashimo H. Neuronal NOS provides nitrergic inhibitory neurotransmitter in mouse lower esophageal sphincter. Am J Physiol 1999; 277: G280-84.

[65] Mearin F, García-González MA, Strunk M, Zárate N, Malagelada JR, Lanas A. Association between achalasia and nitric oxide synthase gene polymorphisms. Am J Gastroenterol 2006; 101: 197984.

[66] Zarate N, Wang XY, Tougas G, et al. Intramuscular interstitial cells of Cajal associated with mast cells survive nitrergic nerves in achalasia. Neurogastroenterol Motil 2006; 18: 556-68.

[67] Micci MA, Kahrig KM, Simmons RS, Sarna SK, Espejo-Navarro MR, Pasricha PJ. Neural stem cell transplantation in the stomach rescues gastric function in neuronal nitric oxide synthase-deficient mice. Gastroenterology 2005; 129: 1817-24.

[68] Bassotti GF, Villanacci V. Slow transit constipation: a functional disorder becomes an enteric neuropathy. World J Gastroenterol 2006; 12: 4609-13.

[69] Ehrström M, Näslund E, Ma J, Kirchgessner AL, Hellström PM. Physiological regulation and NO-dependent inhibition of migrating myoelectric complex in the rat small bowel by OXA. Am J Physiol Gastrointest Liver Physiol 2003; 285: G688-95.

[70] Watkins CC, Sawa A, Jaffrey S, et al. Insulin restores neuronal nitric oxide synthase expression and function that is lost in diabetic gastropathy. J Clin Invest 2000; 106: 373-84.

[71] Surendran S. Fas (CD95) alters neuronal nitric oxide synthase expression to contribute in diabetic gastroparesis. Med Hypotheses 2007; 68: 1427.

[72] Cellek S, Foxwell NA, Moncada S. Two Phases of Nitrergic Neuropathy in Streptozotocin-Induced Diabetic Rats. Diabetes 2003; 52: $2353-62$

[73] Jeyabal PVS, Kumar R, Gangula PPR, Micci MA, Pasricha PJ Inhibitors of advanced glycation end-products prevent loss of enteric neuronal nitric oxide synthase in diabetic rats. Neurogastroenterol Motil 2008; 20: 253-61.

[74] Matsugana N, Anan I, Forsgren S, et al. Advanced glycation end products (AGE) and the receptor for AGE are present in gastrointestinal tract of familial amyloidotic polyneuropathy patients but do not induce NF-kappaB activation. Acta Neuropathol 2002; 104: 441-47.

[75] Goldblatt MI, Swartz-Basile DA, Choi SH, et al. Iron deficiency transiently suppresses biliary neuronal nitric oxide synthase. J Surg Res 2001; 98: 123-28.

[76] Tack J, Demedts I, Dehondt G, et al. Clinical and pathophysiological characteristics of acute-onset functional dyspepsia. Gastroenterology 2002; 122: 1738-47.

[77] Nakamura K, Takahashi T, Taniuchi M, Hsu CX, Owyang C. Nicotinic receptor mediates nitric oxide synthase expression in the rate gastric myenteric plexus. J Clin Invest 1998; 101: 1479-89. 